\title{
Subjetividad en la educación visual contemporánea: algunos componentes
}

\section{Pérez, Juan Manuel}

Resumen:

El artículo analiza la influencia de los distintos elementos de la imagen en el proceso de formación de subjetividades contemporáneas y hace principal hincapié en el señalamiento cómo esos elementos transforman, delimitan y atraviesan la alfabetización visual contemporánea en la búsqueda de subjetividades políticas, estéticas y tecnológicas.

Palabras clave: formación de subjetividades - iconósfera contemporánea - teckné - pedagogías de la enseñanza visual - memoria.

$\left(^{*}\right)$ Profesor y Licenciado en Letras (UBA). Docente en diversas instituciones. Director de estudios de la escuela Motivarte. Miembro del colectivo f: imagen y palabra.

\section{Cuadernos del Centro de Estudios de Diseño y Comunicación Nº 66}

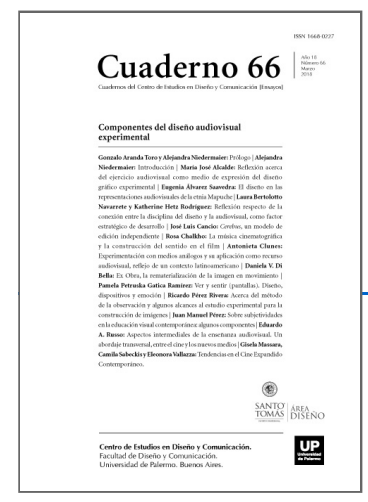

ISSN: 1668-0227

\section{Componentes del}

diseño audiovisual

experimental

Año XVIII, Marzo 2018, Buenos Aires, Argentina | 196 páginas

descargar PDF

ver índice de la publicación

Ver todos los libros de la publicación

compartir en Facebook
Esta obra está bajo una Licencia Creative Commons Atribución-NoComercialCompartirlgual 4.0 Internacional

Introducción: unas palabras sobre el análisis de la iconósfera

A la esfera plástica de imágenes sobre la que pesan los distintos mensajes ideológicos, culturales, morales, o publicitarios, entre otras pulsiones capitalistas contemporáneas, -y en medio de la cual nos movemos cotidianamente- la podemos denominar como iconósfera. Este trabajo analizará las distintas formas y los distintos elementos que la subjetividad contemporánea toma a través de la formación de la iconósfera como materia prima de la educación, de la visualidad y de la misma subjetividad.

Siguiendo el análisis que Roman Gubern (1996) propone con respecto al origen de este entorno imaginístico artificial, podemos ubicarlo durante el proceso de industrialización de las grandes ciudades, dependiendo siempre del avance de los saberes técnicos. 
La iconósfera se habría constituido en las sociedades industrializadas, por lo tanto, tras un siglo que había asistido al invento de tecnologías y de modalidades expresivas de la imagen como la fotografía, la litografía, el cartel, el fotograbado, la narrativa dibujada de los comics, y el cine, medios que densificaron espectacularmente el capital icónico en los espacios privados y públicos de las sociedades urbanas. (p. 107)

Podemos pensar la iconósfera como la estructura plástica donde se asienta el capital icónico de una sociedad, determinado siempre por los modos de ver de cada período histórico y que establece conexiones e interacciones dinámicas tanto entre sus diferentes medios de comunicación como entre sus receptores.

Para visibilizar este campo de imágenes que atomiza la tríada de imaginarios social, político y cultural, es necesario el entrenamiento hermenéutico que distintos métodos y disciplinas de análisis del pensamiento contemporáneo otorgan. En esta dirección, la semiología, la semiótica social, la antropología de la imagen, el análisis de su discurso, la filosofía de la estética comprenden un sistema -aunque no siempre convergente ya que todos los casos recortan o modelan en el fenómeno de la imagen distintos objetos de estudio- que permite, en palabras de Alejandra Niedermaier, "una lectura paradigmática y sintagmática de la visualidad". (2013, p. 2)

La puesta en práctica de una hermenéutica de la imagen sobre la red de la iconósfera contemporánea supone la decodificación de la experiencia visual como principal portadora del modo de "percibir, interpretar y pensar el mundo" (ibid, p. 39). Así, la densidad de la iconósfera nos habla de "su carácter turbador y fronterizo entre lo simbólico y lo real, lo conceptual y lo ontológico, lo mágico y lo existencial” (Gubern, 2004, p. 333). En este punto Niedermaier y Gubern hacen énfasis en el grado de existencialidad de la imagen y apuntan a la posibilidad mágica que la teckné desarrolla en el formato de realidad virtual. Así lo simbólico y lo mágico se cruzan con lo existencial y lo virtual dentro de la misma esfera visual.

\section{La formación de subjetividades}

De la misma manera que la atmósfera de imágenes de una sociedad modifica las relaciones entre las esferas culturales, también hace mella sobre el concepto de subjetividad y tiene una relación de ida y vuelta con la didáctica y la pedagogía de las artes. La imagen, sabemos, es uno de los principales componentes para la construcción de subjetividad en una sociedad y acciona tanto sobre lo inteligible como son el conglomerado de identidades culturales, como sobre lo sensible. Teniendo en cuenta la noción de corporalidad (otro factor decisivo al momento de construir subjetividades e imaginarios) "El cuerpo -afirma Niedermaier leyendo en el dispositivo corporal un nuevo entramado de ideas, pulsiones y tendencias culturales- condensa pensamientos, sueños, recuerdos, es decir, espesores de sentido" (2013, p. 37). En esa dirección la imagen construye identidades sobre las que el discurso visual publicitario actúa confrontando subjetividades con estereotipos y estigmatizaciones. En este sentido, Roman Gubern asocia a la imagen la posibilidad de intervenir y reflejar tanto en el mundo de lo natural como de lo cultural.

Las imágenes, cuando no constituyen espejos (incluso deformantes) de la sociedad que las ha creado, suelen construir espejos elocuentes de sus imaginarios, de sus deseos y sus aspiraciones, de sus sueños reprimidos o prohibidos. Y de ahí surgen los imaginarios heterodoxos, inconformistas, divergentes, clandestinos o subversivos. (2004, p. 324) 
Las actividades estéticas dan cuenta en la actualidad de la evolución de los procesos productivos en su totalidad, de las contradicciones y tensiones que surgen de su práctica y de las subjetividades que se generan en estos nuevos contextos.

En un panorama más local y contemporáneo Graciela Frigerio desde el punteo de impresiones estéticas sobre distintas esferas educativas en su texto "Grülp" señala que estos elementos visuales que intervienen en la construcción de subjetividad no son lejanos a una política de la palabra. Su lectura liga la configuración de una subjetividad estética a la política educativa en cuanto que ambas son formadoras de subjetividades contemporáneas. Esto conlleva a que piense el panorama de la visualidad no como un decorado estético sino como un escenario de batalla donde se desarrollan mecanismos que conforman lazos vinculares. En palabras de Ranciére "dotar de una palabra (en) común es el trabajo de la educación" (2012, p. 40). Formar parte de un colectivo o una comunidad como son un aula y su extensión, una entidad educativa, genera un tener parte/formar parte/ser parte (ibid, p. 41) que consiste, por medio del lazo educativo, de un gesto y un acto político de creación de subjetividades. Siguiendo ese criterio, ofrecer distintos enraizamientos es el más logrado apuntalamiento estético político que la educación otorga a los sujetos-alumnos.

\section{La Teckné como elemento transcultural en la formación de la subjetividad contemporánea}

En la actualidad la iconósfera que nos rodea está atravesada en cuanto a su teckné por los fenómenos de la virtualidad y de las redes sociales que operan de manera directa sobre los distintos tipos de formación de subjetividades. Es útil entonces recordar los postulados de la escuela de Frankfurt al plantear que toda tecnología supone ya en sí misma una ideología. Determinados fines no están solamente en el uso sino, remarcan, ya están en la construcción de los aparatos portadores de la tecnología. La técnica sería un proyecto histórico social donde se proyectan las fuerzas dominantes y los propósitos para distintas esferas sociales (el arte, la literatura, la educación, la política, la religión, etc.) La virtualidad de la imagen y la instantaneidad de las redes sociales atraviesa el capital contemporáneo de la imagen y modifican directa e indirectamente las prácticas en cada una de esas esferas: en arte y educación generan una carrera de arte tecnológico, en literatura y educación una maestría de Tics, en literatura una nueva manera de producir o leer y de relacionarse con sus propios dispositivos tradicionales, en política idean candidatos vacíos de toda reflexión social y a la manera de un ávatar los modelan según las tendencias del mercado. La iconósfera junto con la teckné de una sociedad, construidos como modelos de la episteme de una época, accionan sobre la noción poiesis, sobre la conjunción de paradigmas, produciendo y atravesando nuevas subjetividades, generando nuevas junturas comunicacionales y, dando lugar a hibridaciones artísticas.

La memoria como elemento de formación de subjetividad política

¿Puede la práctica de la fotografía familiar y la reflexión acerca de la imagen fotográfica del álbum familiar, sus intervenciones, sus reproducciones, sus aperturas, proporcionar material para la historia de una generación perdida? La pregunta es una paráfrasis del conocido texto de Pierre Bourdieu (2003) sobre la fotografía como una posible herramienta para el investigador, y pone de relieve el valor contemporáneo de las imágenes rescatadas del álbum familiar de la generación que fue diezmada durante la última dictadura argentina. Retomar esta pregunta ante el panorama ofrecido por la producción de Marcelo Brodsky, 1er, Año, 6ta División, 1967, arroja dos o tres conclusiones no solamente sobre la labor fotográfica en tanto técnica y estética, sino también 
sobre el proceso de revinculación de un país con su propia memoria y, por consecuencia, con su propia identidad. Pero antes de su análisis, recordemos que John Berger argumenta en su libro Mirar, que:

Es posible que la fotografía sea la profecía de una memoria social y política todavía por alcanzar. Una memoria así acogería cualquier imagen del pasado, por trágica que fuera, en el seno de su propia continuidad. Se trascendería la distinción entre los usos privado y público de la fotografía. (2013, p. 72)

De este modo Berger permite asociar de manera poética la noción de memoria a la de fotografía. La fotografía entendida como una herramienta para que la memoria de los hombres se expanda o se desarrolle. El uso aplicado de esta herramienta que despliega la habilidad de la memoria sería trascender las esferas de lo privado y lo público y generar un gran álbum donde esté compendiado toda la humanidad. La fotografía se incorpora al uso de la memoria política y social de todos los hombres y lo que la fotografía puede hacer es restituirle el valor de experiencia a la vida de los hombres.

En Brodsky la producción de un documento que atomiza su propia experiencia escolar marca una generación que atravesó la última dictadura militar. Si "las imágenes nos construyen a nosotros: imponen modos de conducta, condicionan experiencias y puntos de vista e incluso tratan de modelar" (Niedermaier, 2013, p. 38). Las imágenes entonces están ligadas al propio devenir de la memoria colectiva de un país, a la memoria individual de una generación y a la memoria particular de un artista visual que encuentra en las fotos escolares una marca de las sangrientas políticas del gobierno dictatorial de ese período.

En este ejercicio de vasos comunicantes, la fotografía deja de ser una huella de lo real para ser una traza de lo real, para ser su posible transformación. La propia visualidad no es simplemente un entorno físico o perceptivo, sino que constituye un complejo sistema de interacciones entre el sujeto y las imágenes presentes en su espacio social.

La conformación de esta memoria a la que apunta Berger,cargada de significación política y cultural, no puede realizarse sino a partir de un uso alternativo de la fotografía, al que llamaremos, para remarcar su carácter híbrido, de performático y su esencia compleja: el artefacto de la imagen.

La práctica docente como elemento de formación de subjetividad estética

Siguiendo al texto de Niedermaier "Cuando me asalta el miedo, creo una imagen" podemos establecer un proceso de imbricación entre la praxis creativa del productor artístico y la praxis selectiva del docente en tanto creador y curador de contenidos didácticos y disciplinares de una asignatura. Como espigadores, en cuanto a las tramas intertextuales que tejen y a los recortes que realizan para consignar una currícula y organizar sus materiales, los docentes aúnan un punto de vista técnico, un punto de vista estético, un punto de vista ideológico y un punto de vista didáctico. En la materialidad de sus ideas, en la forma de extenderlas al alumnado, en la adaptación de los contenidos existe un tratamiento plástico donde se fragua un conocimiento con marcas de la experiencia personal tanto como de sus propias presunciones e investigaciones (p. 181). La doble cara de esto es que "si se considera a la enseñanza como una propuesta personal de intervención (...) la pedagogía de la imagen resulta un permanente constructo que debe ser revisado periódicamente" (p. 191) de la misma manera que una obra se modifica en el tiempo, los proyectos didácticos piden asimismo una revisión dinámica de sus propósitos y objetivos para ser adecuados a su entorno. 
Sobre este tópico de la renovación, un joven Pierre Bourdieu escribía en su manifiesto sobre la educación universitaria (escrito junto con Jacques Derrida y otros personajes del Collége) que los currículums deberían ser lo suficientemente flexibles y actualizables como para organizar y permitir investigaciones por parte de los alumnos y los docentes, "abiertos, flexibles, revisables, los programas son un marco y no una horca: deben ser cada vez menos constrictivos a medida que nos elevamos en la jerarquía de los órdenes de la enseñanza". (Bourdieu, 2014)

De esta forma como los lenguajes artísticos visuales se entrelazan y convierten al espectador en plausible autor (siguiendo las generalidades de la escuela de la Recepción), la esfera de la docencia engloba tanto al docente como al estudiante: "el conocimiento entre el docente y en el discente. Al envolverlos, los incluye en la escena. Esa inclusión implica el involucramiento, el compromiso de los -docente, alumno-realizador visual". (Niedermaier, 2015, p. 195)

En este sentido, la lógica del espectador emancipado ante las perspectivas del arte contemporáneo puede trasladarse a la del alumno emancipado ante las perspectivas de las nuevas pedagogías en donde colabora con el docente y con el proyecto de la materia generando a partir de disparadores pedagógicos nuevas narrativas o líneas de fuga.

Lo sensible y lo inteligible como elementos de formación de subjetividad cultural

Frigerio admite que "si la transmisión - de sentido a través de las imágenes que generamos- sostiene una lectura de lo sensible y lo inteligible, entones la transición no puede pensarse como una estética no independiente de una ética" (p. 39). Y esta visión se continúa con el fragmento de cita que Niedermaier elige de Agamben, dándole a la imagen un sentido de ubicuidad "La imagen fotográfica es siempre más que una imagen: es el lugar de un descarte, de una laceración sublime entre lo sensible y lo inteligible, entre la copia y la realidad, entre el recuerdo y la esperanza". (2014, p. 36)

Como si el mapa precediera al territorio, la conformación del universo de lo inteligible y de lo sensible está articulada por los distintos caminos de la visualidad contemporánea, así cada una de las esferas se repliega o se desenvuelve sobre las posibilidades teóricas y técnicas que a su propio entorno le corresponde. Frigerio incluye a Legendre cuando realiza el vínculo de imágenes/sociedad, pensando en una fábrica de imágenes como condición de posibilidad elemental para construir una subjetividad que permita fundar las distintas dimensiones de la convivencia humana, "para que haya sociedad es necesario que trabaje la fábrica de imágenes que nos permita construir, ver al otro como semejante y al sujeto como diferenciado, vivir entre otros, con otros, no es sino el efecto de una producción estética. (p. 41)

Como afirma Frigerio, entonces, la relación que se sucede entre las esferas de lo inteligible y lo sensible siempre ha interrogado al hombre, más que nada porque significa un escenario para la propia convivencia y para la propia visión de un mundo que cada grupo social construye a partir de sus condiciones técnicas. "La imagen analógica representaba, señalaba y mostraba el mundo mientras que la imagen híbrida digital, señala, muestra y representa el pensamiento". (Niedermaier, p. 36) En el panorama actual, la segmentación de saberes posibilita la conformación y la combinatoria de distintas prácticas transversales que atomicen lo cultural o lo teórico con lo práctico. Frigerio dice sobre esto que "la rigurosidad de los saberes posibilita la inteligencia de la combinatoria 
entre teoría, estética, producción y vida cotidiana -ya que- el arte es una manera de pensar, de dar a conocer, de compartir y de repartir". (p. 38)

De tal forma, las imágenes proponen una visión del mundo y, como hemos leído, hasta del mundo virtual, sobrenatural e invisible.

Bibliografía

Berger, J. (2012). Mirar. Buenos Aires: De la Flor.

Bourdieu, P. (2014). "9 principios para una reflexión sobre los contenidos de la enseñanza", en Capital cultural, escuela y espacio social. Buenos Aires: Siglo XXI.

Bourdieu, P. (2003). La fotografía, un arte intermedio. Barcelona: GG.

Gubern, R. (2004). Patologías de la imagen. Barcelona: Anagrama. . (1996). Del bisonte a la realidad virtual. Barcelona: Anagrama.

Frigerio, G. (2012). “Grülp” en Educar: sobreimpresiones estéticas. Buenos Aires, Del estante.

Niedermaier, A. (2015). "Cuando me asalta el miedo, creo una imagen”, en Goyez Narvaez Julio Cesar y Niedermaier Alejandra (comp.) Poéticas y Pedagogías de la imagen, Cuaderno n56, Universidad de Palermo. (2013). "La distribución de lo inteligible y lo sensible hoy", en Niedermaier Alejandra y Polo Viviana (comp.) Acerca de la subjetividad contemporánea, Cuaderno n43, Universidad de Palermo.

\section{Abstract:}

The article analyzes the influence of the different elements of the image in the contemporary subjectivity construction process focusing in how those elements transform, delimitate and cross the contemporary visual literacy in the search of political, aesthetics and technological subjectivities.

Key words: subjectivity construction - iconsphere - contemporary - teckné - visual teaching pedagogy - memory

Resumo:

O artigo analisa a influencia dos diferentes elementos da imagem no processo de formação de subjetividades contemporâneas e faz ênfase na observação de como esses elementos transformam, definem e atravessam a alfabetização visual contemporânea na procura de subjetividades políticas, estéticas e tecnológicas.

Palavras chave:

formação de subjetividades - iconosfera contemporânea - tekné - pedagogias do ensino visual - memória. 
Subjetividad en la educación visual contemporánea: algunos componentes fue publicado de la página 135 a página141 en Cuadernos del Centro de Estudios de Diseño y Comunicación № 66 